\title{
Normas para Publicação
}

Os textos submetidos ao periódico Atualidade Teológica, mesmo quando avaliados, revistos e publicados são de total responsabilidade dos seus autores.

Os autores devem ter título de pós-graduação em doutorado.

Os textos deverão ser inéditos. Podem ser pesquisas originais ou textos de revisão. No caso de ser detectado plágio, deverá ser feita, pelo autor, uma retratação, a publicar-se em edição posterior tanto impressa quanto eletrônica.

Os textos, sejam de artigo ou de resenha, uma vez encaminhados para Atualidade Teológica, não devem ser propostos paralelamente a outro periódico. Isso só poderá ser feito se forem antes devolvidos pela revista Atualidade Teológica ou se houver uma desistência de publicação expressa da parte do autor.

As submissões e demais comunicações sobre o processo de avaliação, revisão e publicação do artigo ou resenha serão feitas no Portal de Periódicos do Sistema Maxwell: <http://www.periodicosmaxwell.vrac.puc-rio.br/>. Para outras eventuais informações, os contatos devem ser feitos para o e-mail $<$ atualidadeteologica@puc-rio.br>.

Publicam-se textos científicos de teologia que atendam ao escopo e os objetivos de Atualidade Teológica e que tenham sido aprovados no processo seletivo, que passa pela pré-avaliação, a revisão por pares e os pareceres finais do editor ou de membros do conselho editorial. 
As dimensões previstas para as contribuições são: de 10 a 12 páginas para artigos; e de 2 a 5 páginas para resenhas.

Incluem-se, na extensão prevista, o título, o resumo, as palavras-chave, o corpo do texto, as referências bibliográficas, os dados do autor.

O formato da página é A4.

As margens do documento são; superior e inferior - $3 \mathrm{~cm}$; esquerda e direita $-2,5 \mathrm{~cm}$.

O espaçamento entre as linhas é simples, com $0 \mathrm{~cm}$ para o "antes" e o "depois" de cada parágrafo, que terá $1 \mathrm{~cm}$ adentrado na primeira linha (identação).

A letra deve ser na fonte Times New Roman: caractere 11 para o corpo do texto e caractere 9 para as notas de rodapé.

As citações longas (com três linhas ou mais) deve utilizar caractere 10, sem aspas, com recuo de $1 \mathrm{~cm}$ à esquerda.

Para fontes específicas de palavras ou citações em grego e em hebraico, deve-se entrar em comunicação com a secretaria da revista, e verificar o envio das fontes correspondentes que são usadas pelo periódico.

O título e, se houver, o subtítulo do artigo, ficarão alinhados à direita, utilizando-se a fonte Times New Roman em negrito, caractere 18 para o título e 16 para o subtítulo. Título e subtítulo são separados por dois pontos (:). As resenhas têm como título a referência completa da obra analisada, o que também deve vir alinhado à direita.

Depois do título e do sub-título no idioma original do artigo (o idioma original pode ser em português, espanhol, inglês, francês ou italiano), devem vir o título e o subtítulo traduzidos para o inglês (se não for esse o idioma original). Caso seja em inglês, é desejável que a tradução seja em português.

O nome do autor do artigo ou resenha aparecerá duas vezes: no início do texto, abaixo do título-subtítulo, alinhado à direita, fonte Times New Roman itálico e caractere 12; e no final do texto, alinhado à direita, fonte Times New Roman itálico-negrito e caractere 12.

Apresentam-se o resumo (de 150 a 200 palavras) e as palavras-chave (5 no máximo). Em seguida sua tradução para o inglês - do "abstract" e "keywords". Caso seja em inglês, é desejável que a tradução seja em português.

O corpo do artigo deve ter: a Introdução; as várias partes numeradas em algarismos arábicos com suas subdivisões, separando-se os algarismos por pontos. Por exemplo: 1. / 1.1. / 1.2. / 1.2.1. / 1.2.2 /... Ao final de cada seção salta-se uma linha. Ao final, Conclusão. 
Segue a apresentação de referências bibliográficas, nas quais devem constar todas as referências do artigo, em ordem alfabética, mas somente aquilo que foi citado (direta ou indiretamente).

Após o nome do autor no final do texto, devem ser dadas as seguintes informações, cada uma em uma linha, todas alinhadas à direita: o nome do autor, em negrito e itálico; a maior titulação do autor e a instituição de ensino que lhe deu o título; sua filiação institucional e função na instituição; cidade, CEP e país da instituição à qual está filiado; e-mail para contato.

A indicação das referências bibliográficas ao longo do texto, para citações diretas ou indiretas, é feita em notas de rodapé.

Para as indicações bibliográficas nas notas de rodapé e nas referências ao final, faz-se uso das normas da ABNT (norma NBR 6023), mas com adaptações previstas nas "Normas de Pós-Graduação da PUC-Rio" conforme mostrado nos exemplos a seguir.

\section{Citação de obras impressas}

\section{Um autor}

Referências bibliográficas:

KUZMA, C. O futuro de Deus na missão da esperança: uma aproximação escatológica. São Paulo: Paulinas, 2015.

Notas bibliográficas:

KUZMA, C., O futuro de Deus na missão da esperança, p. 8.

\section{Dois autores ou três autores}

Referências bibliográficas:

LIBÂNIO, J. B.; BINGEMER, M. C. L. Escatologia Cristã. Rio de Janeiro: Vozes, 1996.

Notas bibliográficas:

LIBÂNIO, J. B.; BINGEMER, M. C. L., Escatologia Cristã, p. 18.

\section{Mais de três autores}

Referências bibliográficas:

MILANI, A. L. et al. Introdução ao Segundo Testamento: eu vim para que todos tenham vida. São Paulo: Paulus, 2007.

Notas bibliográficas:

MILANI et al., Introdução ao Segundo Testamento, p. 96. 


\section{Organizador ou Editor}

Referências bibliográficas:

LIMA, L. C. (Org.). Teologia e Sexualidade: portas abertas pelo Papa Francisco. São Paulo: Editora Reflexão, 2015

ZUCK, R. B. (Ed.). Teologia do Antigo Testamento. Rio de Janeiro: CPAD, 2009.

\section{Mais de uma editora}

PÉDROSA-PÁDUA, L.; CAMPOS, M. B. (Orgs.). Santa Teresa: mística para o nosso tempo. São Paulo: Editora Reflexão; Rio de Janeiro: Editora PUC-Rio, 2011.

BINGEMER, M. C. L.; ANDRADE, P. F. C. (Orgs.). O Censo e as religiões no Brasil. Rio de Janeiro: Editora PUC-Rio; São Paulo: Editora Reflexão, 2015.

\section{Editoras de um mesmo local}

AMADO, J. P.; FERNANDES, L. A. (Orgs.). Cultura da Paz num mundo em conflito. Rio de Janeiro: Editora PUC-Rio / Letra Capital, 2017.

\section{Autor desconhecido}

IMITAÇÃO de Maria. São Paulo: Cultor de Livros; São Paulo: Editora Cleofas, 2015.

\section{Autor entidade}

CELAM. A Igreja na atual transformação da América Latina à luz do Concílio: conclusões da II Conferência Geral do Episcopado LatinoAmericano, Medellín, 1968. Petrópolis: Vozes, 1970.

CNBB. O Estado que temos e o Estado que queremos. Estado para que e para quem? Brasília: Edições CNBB, 2014.

PONTIFÍCIA COMISSÃO BÍBLICA. Inspiração e verdade da Sagrada Escritura: a palavra que vem de Deus e fala de Deus para a salvação do mundo. São Paulo: Paulinas, 2014.

\section{Editora não informada}

FRANCO, I. Discursos: de outubro de 1992 a agosto de 1993. Brasília: [s.n.], 1993. 


\section{Obra em diversos volumes}

WIEDERKEHR, D. Cristologia sistemática. In: FEINER, J.; LÖHRER, M. Mysterium Salutis: compêndio de dogmática histórico-salvífica. Petrópolis: Vozes, 1973. v. III / 3. 2.

\section{Capítulo ou parte unitária de um livro}

LIMA, M. L. C. Desagregar e reintegrar: a guerra como punição em Os 10,915. In: AMADO, J. P.; FERNANDES, L. A. (Orgs.). Cultura da Paz num mundo em conflito. Rio de Janeiro: Editora PUC-Rio / Letra Capital, 2017. p. $89-119$.

\section{Referência a periódicos}

ATUALIDADE TEOLÓGICA. Rio de Janeiro: PUC-Rio / Letra Capital, 1997-2018. Quadrimestral.

\section{Artigos de periódicos}

CARDOSO, M. T. F. Diálogo da misericórdia: estudo sobre um tema da Bula Misericordiae Vultus do Papa Francisco. Atualidade Teológica, v.20, n.54, p. 599-622, set./dez. 2016.

\section{Artigos de revista eletrônica}

SILVA, A. L. R. A visão de São Justino sobre a mulher: personagens e notícias. Atualidade Teológica, v.19, n.51, p. 529-545, set./dez. 2015. Disponível em: $<$ https://www.maxwell.vrac.puc-rio.br/25865/25865.PDFXXvmi=>. Acesso em: 12 jun. 2018.

\section{Resumo de artigos de periódicos}

MORAES, A. Desafios e perspectivas à Pastoral. Familiar a partir da Amoris Laetitia. Atualidade Teológica, v.20, n.54, p. 580-598, set./dez. 2016. Resumo.

\section{Artigo de jornal}

BERTONE, T. O Pai-Nosso deve ressoar na vida do cristão. L'Osservatore Romano, Roma, 31 jul. 2010. p. 1.

BINGEMER, M. C. L. A desordem que o amor faz. Jornal do Brasil, Rio de Janeiro, 28 fev. 2018. Disponível em: <http://m.jb.com.br/artigo/ noticias/2018/02/28/a-desordem-que-o-amor-faz/>. Acesso em: 12 jun. 2018. 


\section{Teses e Dissertações}

PERNAMBUCO, M. N. Os textos doxológicos no contexto do livro, em especial relação com Am 1,1; 8,8 e 9,1: a relevância da menção do terremoto na mensagem do livro. Rio de Janeiro, 2012. 116p. Dissertação. Faculdade de Teologia, Pontifícia Universidade Católica do Rio de Janeiro.

\section{Anais de Congresso}

CONGRESSO INTERNACIONAL DA SOTER, 30., 2017, Belo Horizonte. Anais... Belo Horizonte: PUC-Minas, 2017, 1591p.

CONGRESSO INTERNACIONAL DA SOTER, 30., 2017, Belo Horizonte. Anais... Belo Horizonte: PUC-Minas, 2017. Disponível em: $<$ http://www. soter.org.br/anais/30.pdf>. Acesso em: 12 jun. 2018.

\section{Trabalhos apresentados em congressos ou outros eventos acadêmicos} ARAGÃO, G.; PANASIEWICZ, R.; RIBEIRO, C. O. Pluralidade Espiritual e Diálogo Inter-Religioso. In: CONGRESSO INTERNACIONAL DA SOTER, 30., 2017, Belo Horizonte. Anais... Belo Horizonte: PUC-Minas, 2017. Disponível em: <http://www.soter.org.br/anais/30.pdf >. Acesso em: 12 jun. 2018.

\section{Verbete de dicionário}

COURT, J. M. Millenarianism. In: COGGINS, R. J.; HOULDEN, J. (Eds.). A Dictionary of Biblical Interpretation. London: SCM Press, 1990. p. 459-461.

\section{Bíblia}

BÍBLIA de Jerusalém. Nova ed. rev. e ampl. 2. impr. São Paulo: Paulus, 2003.

\section{Diversos}

Referências bibliográficas:

CÓDIGO de Direito Canônico. São Paulo: Loyola, 2001.

Notas bibliográficas:

CIC Cân. 6, §2.

Referências bibliográficas:

CATECISMO DA IGREJA CATÓLICA. Petrópolis: Vozes; São Paulo: Paulinas: Loyola, 1993.

Notas bibliográficas:

CEC 215. 
Referências bibliográficas:

CNBB. Comunidade de comunidades: uma nova paróquia. Brasília: Edições CNBB, 2014. (Doc. 100).

Notas bibliográficas:

CNBB, Doc. 100, 5.

Referências bibliográficas:

COMISIÓN TEOLÓGICA INTERNACIONAL. Documentos 1969-1996:

Veinticinco años de servicio a la teología de la Iglesia. Madrid: BAC, 1998.

(Biblioteca de Autores cristianos, 587).

Notas bibliográficas:

CTI, Veinticinco años de servicio a la teología de la Iglesia, 5.

Referências bibliográficas

DENZINGER, H. Compêndio dos símbolos, definições e declarações de fé e moral. Traduzido com base na $40^{\mathrm{a}}$ edição alemã (2005), aos cuidados de Peter Hünermann. São Paulo: Paulinas / Loyola, 2007.

Notas bibliográficas:

DH 3414.

Referências bibliográficas:

FRANCISCO, PP. Exortação Apostólica Evangelii Gaudium sobre o anúncio do Evangelho no mundo atual. Brasília: Edições CNBB, 2013.

Notas bibliográficas:

EG 14.

Referências bibliográficas:

TOMÁS DE AQUINO. Suma Teológica: a fé, a esperança, a caridade, a prudência: II seção da II parte, questões 1-56. São Paulo: Loyola, 2004. v. 5. Notas bibliográficas:

ST II, II, q. 1-56.

Conteúdo, correção linguístico-ortográfica, forma e estilo dos textos submetidos são de inteira responsabilidade dos seus autores. A revista pode fazer sugestões ou exigências de revisão, mas fica isenta de responsabilidades, encargos ou ônus a esse respeito. 
Os autores e as autoras serão notificados quanto à aprovação ou não do texto submetido.

Se a contribuição for aprovada, os direitos autorais são cedidos à Atualidade Teológica e fica autorizada a publicação do artigo ou da resenha nas duas formas de publicação da revista: impressa e eletrônica.

Pelos direitos autorais cedidos, os autores e autoras receberão três exemplares da revista impressa quando tiverem contribuído com um artigo ou uma resenha.

$\mathrm{O}$ autor deve preencher, assinar e encaminhar para o e-mail da revista o formulário de autorização para publicação online. Tal formulário encontra-se no site da revista, na aba "Normas". O link para o formulário é: $<$ https://www. maxwell.vrac.puc-rio.br/18383/18383.PDFXXvmi=>. Essa autorização será válida para o caso de o artigo ser aprovado e a sua publicação confirmada pela revista (na forma final do texto após as revisões propostas pela revista e aceitas pelo autor). 